\title{
Crônica de uma resistência anunciada: os traços da distopia crítica em Bacurau, de Kléber Mendonça Filho e Juliano Dornelles
}

\author{
José Wanderson Lima Torres a \\ Wagner dos Santos Rocha ${ }^{b}$ (1)
}

\begin{abstract}
RESUMO
A distopia é um desdobramento da utopia literária que ganhou força especialmente no início do século $X X$, demonstrando uma habilidade singular em discorrer sobre temáticas sociopoliticas atuais através de um "espelho manchado do porvir". O texto distópico possui uma predisposição para a narrativa que a aproxima de variados gêneros artísticos e discursivos ao contar a vivência de uma ou mais pessoas num futuro próximo, ou não, em que a ordem social proposta é considerada pior do que aquela que existe na realidade. A partir dos anos 1980, críticos e teóricos que estudam o tema sinalizaram uma "guinada distópica", em que narrativas desse cunho começaram a apresentar vislumbres de esperança em meio ao caos característico da temática com o advento das chamadas distopias críticas. Tomando as considerações acima, o presente trabalho analisa o longa-metragem recente dos diretores brasileiros Kléber Mendonça Filho e Juliano Dornelles, Bacurau (2019), como uma distopia crítica. O filme, que situa
\end{abstract}

a Universidade Estadual do Piauí, Programa de Pós-Graduação em Letras, Teresina, PI, Brasil.

E-mail: wandersontorres@hotmail.com

b Universidade Estadual do Piauí, Programa de Pós-Graduação em Letras, Teresina, PI, Brasil.

E-mail: wagner.rocha.lp@gmail.com

\section{Como citar:}

TORRES, J.W.L.; ROCHA, W.S. Crônica de uma resistência anunciada: os traços da distopia crítica emBacurau, deKléber Mendonça Filhoe Juliano Dornelles.Gragoatá, Niterói, v.26,n.54, p.718-748, 2021. 
sua narrativa no sertão pernambucano "daqui a alguns anos", apresenta a união de uma comunidade contra a tensão constante de forças externas que trabalharam para sua destruição, restando-lhes apenas o senso de resistência já arraigado em sua história. Procura-se, assim, discorrer sobre esse tipo específico de distopia e como ele está presente dentro da narrativa do filme, transformando-o em um material de aguçada crítica social e política. A presente pesquisa é de cunho bibliográfico e caráter exploratório, apoiando-se teoricamente em nomes como Sargent (1994), Baccolini (2003) e Moylan (2016).

Palavras-chave: Distopia crítica. Utopismo. Bacurau.

Vim aqui só pra dizer Ninguém há de me calar Se alguém tem que morrer Que seja pra melhorar

Réquiem para Matraga, Geraldo Vandré

${ }^{1} \mathrm{O}$ filme concorreu em quinze categorias do prêmio, vencendo em seis delas: Melhor filme, melhor direção, melhor roteiro original, melhor ator (Silvero Pereira), melhor montagem de ficção e melhores efeitos visuais.

\section{Considerações iniciais}

Sucesso de crítica e público, o quarto longa-metragem do pernambucano Kléber Mendonça Filho, codirigido e corroteirizado com Juliano Dornelles, Bacurau, surpreendeu a plateia do Festival de Cannes, ganhando o Prêmio do Júri, o terceiro mais importante da premiação, e aos poucos se tornando um grande achado do cinema brasileiro em 2019. Desde então, o filme teve mais de noventa convites para participar de festivais de cinema ao redor do mundo e foi premiado em lugares como Munique, Sidney, Lima, e, mais recentemente, no Grande Prêmio do Cinema Brasileiro ${ }^{1}$, tornando-se o maior vencedor da edição de 2020. Além disso, estreou em diversos países apenas reconfirmando o seu potencial, que mescla uma intensa experiência narrativa e crítica. 
2 Emilie Lesclaux é montadora e produtora de filmes. Nascida na França, vive no Brasil desde 2002, onde se casou com Kléber Mendonça Filho, e foi produtora de seus filmes como Recife frio, $\mathrm{O}$ som ao redor e também Bacurau.
Quanto aos realizadores, Mendonça Filho é formado em jornalismo e iniciou a sua carreira como crítico escrevendo para o Jornal do Commercio e para um site de sua autoria, o CinemaScópio, mesmo nome dado a sua atual produtora, a qual é coordenada junto à Emilie Lesclaux. ${ }^{2}$ Sua carreira cinematográfica iniciou-se em 1997, quando lançou o médiametragem Enjaulado; depois disso, continuou a trabalhar com curtas-metragens com destaque para os premiados Vinil Verde (2004), Eletrodoméstica (2005) e Recife frio (2009); por fim, dedicouse a produções mais longas, começando pelo documentário Crítico em 2008, seguido de suas realizações mais famosas, os longas-metragens de ficção $O$ som ao redor (2012) e Aquarius (2016). Dornelles, por sua vez, iniciou no cinema dirigindo o curta Biodiversidade (2005) ao lado de Daniel Bandeira, mas firmou seu terreno com as colaborações feitas com Mendonça Filho na direção de arte de seus filmes, nos quais também trabalhou como produtor.

Em Bacurau, a jovem médica Teresa retorna à comunidade sertaneja homônima onde cresceu no oeste de Pernambuco quando descobre quesua avó, Carmelita, faleceu repentinamente. A história é situada "daqui a alguns anos" e mostra como este pequeno lugar, isolado espacialmente, sofre com problemas de abastecimento de recursos básicos, como água e saúde, mas que, ainda assim, consegue resistir às provações e se manter de pé, mesmo com todas as adversidades. No entanto, com a morte de anciã, acontecimentos insólitos começam a surgir, como o inesperado desaparecimento da cidade do mapa e o aparecimento de perigosos estrangeiros dispostos a dizimar qualquer vestígio de vida presente no lugar, o que preocupa os moradores que, aos poucos, se preparam para enfrentar os perigos de todas as maneiras possíveis.

Resistência é provavelmente a palavra mais significativa para entender Bacurau. Construído a partir da junção de diversos gêneros como ação, western e ficção científica, o filme traz em seu argumento uma acentuada carga política que dialoga com diversos problemas político-estruturais do país. Em entrevista, o diretor afirma que:

Queria fazer uma história de ação, aventura, mas que também tratasse de questões que são cíclicas, crônicas no Brasil. Ponho na tela, por exemplo, a separação invisível e histórica entre Sul 
e Sudeste, de um lado, e o Nordeste, de outro. A desigualdade está retratada lá, assim como o problema do abastecimento de água, o político corrupto, os supremacistas brancos, o caminhão que despeja livros no meio da rua, o descaso com a educação (MENDONÇA FILHO, 2019, s/p).

Logo, devemos compreendê-lo como um filme de gênero (ou de gêneros), que cumpre seu papel crítico de questões atreladas ao aspecto social brasileiro, construindo um cenário crítico singular e que merece a atenção devida.

Em seus 132 minutos, o filme consegue dialogar com questões inerentes ao espectro político e histórico do país, sendo a principal delas o descaso com as regiões mais inóspitas do país e como os sujeitos que nelas habitam são vistos como seres domináveis, propícios a se deixarem levar por qualquer um que surja apontando uma melhoria, por mais pífia que ela seja. A comunidade de Bacurau serve exatamente para contrapor esse pensamento ao mostrar personagens que têm consciência dos problemas com os quais vivem e que, além disso, não se calam diante deles, até mesmo revidando violentamente para manter seu espaço.

Em meio aos muitos gêneros presentes em Bacurau, podemos relacioná-lo com a distopia, em razão de sua narrativa de tons futurísticos e caóticos, e mais especificamente, com a distopia crítica, uma categoria análoga à primeira que se tornou corrente a partir dos anos 1980, ao realizar uma intervenção textual na forma distópica, "uma vez que negaram a negação do momento crítico-utópico e, dessa forma, abriram espaço para uma nova manifestação da imaginação utópica dentro das distopias" (MOYLAN, 2016, p. 151). Pensando nisso, o presente trabalho traça considerações sobre a distopia e a distopia crítica, a fim de perceber estes traços na narrativa de Bacurau. O trabalho se divide em duas seções: na primeira, observamos a distopia enquanto desdobramento do utopismo e da utopia literária, bem como seus desdobramentos enquanto narrativa; e, na segunda, relacionamos a narrativa do filme com os aspectos distópico-críticos, compondo um diálogo que confirme sua correlação. 


\section{De relativismos utópicos e distópicos}

Herdeira direta das ansiedades crescentes do século XX, a distopia adquiriu respaldo ao tratar de temáticas contrárias ao senso comum de diversas pedras-de-toque da modernidade. Em uma realidade onde a tecnologia e a industrialização, bem como o racionalismo, eram regentes supremos, esta temática literária surge como uma aura medonha e zombeteira, mas também reflexiva, pois fez com que aos poucos, as possibilidades dadas como certas pelas perspectivas progressistas e científicas não fossem tão absolutas como pareciam.

A distopia advém da antiga tradição utópica iniciada por Thomas More no início do século XVI, quando publica Utopia (1516). Livro basilar na construção de um pensamento pautado no bem-estar social, a obra moreana foi responsável por dar nome a uma manifestação intrínseca ao pensamento humano e que, segundo Sargent (1994, p. 3), esteve presente dentro do imaginário humano desde o início dos tempos. A essa propensão, o crítico americano chamou utopismo, o qual se baseia na ideia de um sonho social, ou seja, é uma atitude inerente ao ser humano e que está relacionada à imaginação e ao desejo por um lugar no tempo e no espaço que seja radicalmente diferente de sua situação.

O conceito tem respaldo na teoria da utopia, de Ernst Bloch, o qual chama estes devaneios de "sonhos diurnos", isto é, pensamentos de livre escolha que moveriam os seres humanos a saciar seus desejos, não apenas em uma perspectiva egoísta, mas também através da ponderação e do planejamento de mudanças num campo externo. Diferentemente das correntes psicanalíticas, que acreditavam que apenas as crianças seriam portadoras destes sonhos, o filósofo observa que os sonhadores diurnos, na verdade, são adultos, "plenos da vontade consciente que permanece consciente para uma vida melhor, ainda que em graus diferenciados" (BLOCH, 2005, p. 92). Por isso, divide estes sonhos em quatro caracteres: "o livre curso", "o ego preservado", "a melhoria do mundo" e o "ir até o fim", isto é, começam com os pensamentos humanos ao léu, passando por uma atitude que se ligaria a outras e que seriam benéficas não apenas ao sonhador, mas também a outros, representando-os.

A partir de suas pesquisas, Sargent (2010, p. 5) antevê a existência de três formas de se pensar acerca do utopismo, as 
${ }^{3}$ Body utopias, no original (tradução nossa).

${ }^{4}$ City utopias, no original (tradução nossa). quais ele nomeia de faces. São elas: a prática utópica, ou seja, a concretização na realidade dos pensamentos utópicos, das quais os maiores exemplos são as comunidades intencionais; a teoria social utópica, que estuda a ideia de utopia a partir do espectro sociopolítico; e a utopia literária, que envolve os objetos literários que discutem a utopia e que são divididos em dois tipos principais: as utopias do corpo ${ }^{3}$ (os mitos e criações de lugares melhores e envolvem apenas a idealização, como a Era de Ouro Grega e o Jardim do Éden); e as utopias de cidade ${ }^{4}$ (criações que envolvem a ação humana, normalmente descritas em projetos minuciosos como são as obras que definiram o gênero literário) (SARGENT, 1994, p. 4).

Para este trabalho, iremos nos ater à face literária, a mais conhecida das três, sobretudo pela influência de More e também por suas propriedades narrativas, importantes para o cinema. Contudo, deve-se levar em consideração que eventualmente as três partes do espectro utopista se conectem a fim de alcançar seus objetivos. Em um exercício extenso de taxonomia, Sargent (1994) categoriza com cuidado as manifestações textuais pertencentes à utopia literária, ofertando ao leitor uma série de conceitos importantes para pensar acerca destes escritos. Mesmo que o método de conceituação pareça engessar o pensamento em torno do fenômeno, o trabalho do autor americano tenta construir uma dimensão precisa no que tange às formas pelas quais o utopismo se apresenta, o que dá oportunidade aos pesquisadores de orientar seus estudos. No caso da utopia literária, o autor a subdivide em sete formas textuais características: utopia, eutopia, distopia, utopia crítica, distopia crítica, sátira utópica e antiutopia.

Utopia, assim como suas correspondentes, advém do grego, num jogo etimológico proposto por More em sua obra, a qual constrói "a melhor das repúblicas" (MORE, 2016, p. 79), na tentativa de moralizar os vícios da sociedade europeia do século XVI. O termo associa as palavras oue -topos, respectivamente não e lugar, ou seja, um lugar inexistente no espaço e no tempo, normalmente a fim de conferir o bem-estar social. Pensada a princípio como uma crítica, a obra conseguiu resistir ao status de ficção e se tornou uma forma de pensamento indissociável à era moderna, bem como às posteriores, recuperando aspectos inerentes à "própria gênese da sociedade como construção histórica, isto 
${ }^{5}$ A palavra surgiu pela primeira vez na introdução da primeira edição de Utopia, através de um poema de seis linhas em que o eu-lírico conta sobre as maravilhas da ilha de Utopia, e como é tão boa que poderia ser chamada de Eutopia. O termo é utilizado para enfatizar que determinada obra descreve uma sociedade melhor. A equivalência entre as palavras "utopia" e "eutopia" é mais evidente no idioma inglês, no qual ambas possuem a mesma pronúncia.

${ }^{6} \mathrm{O}$ neologismo foi colocado por John Stuart Mill em 1868, o qual contrapõe o sentido de "utopia", mas já havia aparecido em um poema do século XVIII atribuído a Henry Lewis Younge, grafado como "dustopia" e significando "país ruim". é, no estabelecimento de pressupostos comportamentais que assegurariam a estabilidade" (PAVLOSKI, 2014, p. 34).

As palavras eutopia e distopia, por sua vez, funcionam como extensões do conceito anterior, mas que expressam pontos de vista dissonantes. A primeira é constituída a partir de outra possível interpretação do neologismo de More, ${ }^{5}$ composta pelo prefixos gregos eu- (bom) e -topos (lugar). O termo foi adotado para se referir a todos os trabalhos que versem sobre bons lugares, ou seja, ideais a serem seguidos por outras nações como A cidade do sol (1602), de Tommaso de Campanella. Já a palavra distopia é composta pelo prefixo dys- (mau), o que lhe confere uma negatividade diante da forma anterior, ${ }^{6}$ tendo sido pensada a partir do fato de que nem sempre os seres humanos imaginam um outro lugar que seja benévolo e prudente, pois, da mesma forma que estamos sujeitos a sonhar, também podemos ter pesadelos.

O espectro utopista se expandiu desde a obra de More, estando presente em diversas obras, a princípio sob o signo da eutopia, e mais tarde sob o da distopia, isto porque, como afirma Pavloski, "a cada novo fluxo de racionalismo na história do pensamento é perceptível o surgimento de tendências fortemente reacionárias" (PAVLOSKI, 2014, p. 41), o que culminou em um relativismo filosófico que inflou críticas ao pensamento utópico. Nisto, observamos que ao tratarem de aspectos relativos ao espaço-tempo, essas manifestações possuem um caráter cronotópico, assim como nos termos de Bakhtin, o qual percebe que, na literatura, "o processo de assimilação do tempo, do espaço, e do indivíduo que se revela neles, tem fluído complexa e intermitentemente" (BAKHTIN, 1990, p. 211). Este é um argumento que se confirma ao analisarmos as épocas de maior proliferação tanto da eutopia (século XIX) como da distopia (primeira metade do século XX), as quais dialogam respectivamente com o progresso científico e tecnológico e com a consequente desilusão com estes.

Dessa forma, a distopia se consolida ao longo do século XX, uma época embebida de pessimismo e com saídas desastrosas, mas que ainda assim tenta se ancorar a uma réstia de esperança, mesmo que esta pareça inexistente. São esses textos ambíguos como Nós (1924) de Zamiátin, Admirável mundo novo (1932) de Huxley e 1984 (1949) de Orwell, ora pessimistas ora esperançosos, os melhores representantes desse quadro. Tal 
7 Utopia serves as a mirror to contemporary society, pointing to strengths and weakness (tradução nossa). qual as eutopias do século anterior, eles surgem em meio a uma mudança de caráter nas relações sociais, quando as eutopias começam a soar como uma idealização autocrática que tem como objetivo absorver a individualidade num caminho fácil ao totalitarismo. Para isso, surge o conflito entre uma verdade preconizada e a dúvida de um ou mais indivíduos que não se encaixam à realidade colocada.

Assim funciona a distopia, um tropo narrativo que se assenta numa era em que o dito paraíso foi perdido e a raça humana parece não conseguir reaver o seu lugar ideal. Contudo, como muitos autores preconizam, essas manifestações não devem ser encaradas como o fim, mas uma nova forma de encarar a realidade, afinal, "a utopia serve como um espelho para a sociedade contemporânea, apontando para seus pontos fortes e fracos ${ }^{7 \prime \prime}$ (SARGENT, 1994, p. 27), ou seja, devemos vê-las como um produto autoconsciente dentro de um pessimismo militante. Moylan afirma com clareza acerca da

[...] necessidade de uma rigorosa avaliação pessimista do momento, sem nunca sucumbir a essa avaliação; mas, ao invés disso, manter o poder mobilizador da esperança utópica que nos puxa para fora da escuridão e em direção ao horizonte transformado (MOYLAN, 2016, p. 22).

Assim, por mais desalentadoras que algumas das narrativas distópicas possam parecer, elas funcionam mais como um aviso do que uma desistência, pois, ao se fundarem no conflito, catalisam a essência do ser humano (BERLIN, 1991, p. 21), e ao proporcionarem isto, todos os autores distópicos permitem que o sonho de mudança ainda possa ser continuado.

Durante os anos 1960 e 1970, o relativismo proposto por Pavloski se acentua mais uma vez. Depois de uma primeira metade dominada por obras de teor distópico, apontada para os terrores do totalitarismo e da massificação cultural, a utopia "renasce" em diversas obras. Vale lembrar que, nesta época, o estudo das propriedades utópicas com finalidades acadêmicas entrou em voga, preocupação essa que surgiu sobretudo em razão dos levantes sociais ocorridos na França e nos Estados Unidos que "contribuíram para entender melhor tradições radicais e visões alternativas, particularmente nos Estados Unidos, onde a Guerra Fria e o McCarthismo quase silenciaram uma geração de ativistas"8 (FITTING, 2009, p. 121). 
${ }^{8}$ contributed to efforts to understand better radical traditions and alternative visions, particularly in a US in which the Cold War and McCarthyism had nearly silenced a generation of activists (tradução nossa).

${ }^{9}$ Dystopian turn, no original. Tradução de Pedro Fortunato. MOYLAN, Tom. Distopia: fragmentos de um céu límpido. Maceió: Edufal, 2016.
Na literatura, essa "ressurreição" foi sentida sobretudo no campo da ficção científica, que em suas estruturas narrativas de caráter especulativo aglutinou o caráter visionário da utopia, fazendo-a recobrar a força.

No entanto, mesmo que a utopia volte novamente a ser a manifestação textual dominante desta década, podese perceber que ela sofreu modificações significativas em seu interior, as quais dialogavam diretamente com as novas tendências teóricas e críticas provenientes do período, como é o caso do feminismo. A fim de abarcar esta retomada da forma textual, Moylan (1986) cunhou o termo "utopia crítica", que diz respeito às obras cuja preocupação central "é a conscientização das limitações da tradição utópica, de modo que os textos rejeitem a utopia como um plano, preservando-a como um sonho" (MOYLAN, 1986, p. 10). Um exemplo desse tipo de texto é Woman on the edge of time (1976) de Marge Piercy, que pode ser lido como uma utopia crítica desde que a autora mostra as limitações do gênero utópico, a partir de uma tendência "a reduzir visões alternativas a sistemas perfeitos fechados e chatos que negam o impulso utópico que os gera" (MOYLAN, 1986, p. 151).

Então, a utopia crítica consiste em uma narrativa utópica que critica o próprio gênero, pois elas assumem a possibilidade do bom lugar, mas, ao mesmo tempo, não a consideram como ideal de perfeição e/ou solução final para os problemas humanos, os quais foram os principais alvos para uma crítica antiutópica na primeira metade do século XX. Assim, além de renovar o gênero, ao transformá-lo em um tipo narrativo, foi possível contrapor as posições divergentes a ele, demonstrando que tais argumentos seriam infundados, já que observavam as utopias a partir de uma visão unilateral.

Ainda que o estudo das utopias e as utopias críticas tenham sido importantes para a reconstrução de uma esperança após a Guerra, foi inevitável que houvesse outra virada para a distopia, ou "guinada distópica" ${ }^{\prime \prime}$, nos termos de Moylan, a qual ocorreu nos anos 1980, quando a distopia ressurgiu dentro dos parâmetros da ficção científica (MOYLAN, 2016, p. 138). Em resposta ao intenso conservadorismo adotado na época, sobretudo com vitórias políticas de Ronald Reagan e Margaret Thatcher, esses novos textos exploraram diversas facetas da 
dominação humana, mais uma vez se atentando ao momento em que foram escritas.

Enquanto nas distopias originais, as maiores preocupações eram o avanço do coletivismo e a barbárie, os textos dessa guinada distópica preocupam-se com o silenciamento das minorias e a destruição do meio ambiente, ambos preconizados pela "repetida afirmação dos sistemas dominantes, de caráter androcêntrico, heterossexual, etnocêntrico, classista e capitalista" (CAVALCANTI, 2011, p. 3). São exemplos desse segmento romances como $O$ conto da aia (1985) de Margaret Atwood, He, she and it (1991) de Marge Piercy e Parábola do semeador (1993) de Octavia Butler.

Assim como os textos das décadas anteriores, estas distopias também receberam o nome de críticas, e, assim como suas predecessoras, retomaram aqueles textos produzidos no início do século, mas também se diferenciando deles ao negociarem

[...] o pessimismo necessário da distopia genérica com uma postura utópica aberta e militante que não apenas rompe com o fechamento hegemônico dos mundos alternativos ficcionais, mas também recusam, autorreflexivamente, a tentação antiutópica que persiste como um vírus cristalizado em toda narrativa distópica (MOYLAN, 2016, p. 21).

Assim, ocorre novamente uma subversão do esquema narrativo anterior e já delineado pela crítica, que alimentará um enclave eutópico que possa funcionar a partir de um "pessimismo militante" (MOYLAN, 2016, p. 152), assim, observa-se que na distopia crítica é importante avaliar a realidade de forma pessimista, mas sem nunca ceder a esta ideia, sempre mantendo um horizonte de esperança.

Essa reestruturação é importante, pois demonstra o potencial utópico que também revolve a distopia, que mais do que nunca transita entre um pessimismo itinerante e uma esperança latente. Com isso, "elas se deixam demorar nos terrores do presente ao mesmo tempo que exemplificam o que é necessário para transformá-lo" (MOYLAN, 2016, p. 159), então, mais do que nunca, o texto distópico cumpre sua proposta de perceber os aspectos nocivos do mundo em que se vive, com um apelo para que o leitor perceba e crie um senso crítico 
${ }^{10}$ Gender blurring, no original. para não deixar que a esperança desapareça no horizonte de possibilidades em que está.

Com este breve panorama, é possível antever a discussão que iremos propor ao argumento de Bacurau. A possibilidade de leitura distópico-crítica no filme de Mendonça Filho e Dornelles se torna possível à medida que observamos a construção de uma narrativa de resistência a barbárie e uma consequente possibilidade de sucesso aos horrores a que a comunidade do longa-metragem enfrenta.

A fim de compreender nosso empreendimento analítico, devemos ter em mente que "o típico texto distópico é um exercício em uma forma de textualidade híbrida politicamente carregada" (MOYLAN, 2016, p. 79). Esta característica, que recebe o nome de hibridismo de gênero ${ }^{10}$ (BACCOLINI; MOYLAN, 2003, p. 6), diz respeito à capacidade que a distopia possui de incorporar aspectos de narrativas como a fantasia, o romance histórico e, o principal deles, a ficção científica, apenas para citar alguns. Esta propriedade também permite a contaminação saudável entre os gêneros literários e, ao mesmo tempo, faz com que haja uma dificuldade de definição.

Tendo isto em mente, essa "dispersão distópica" também é perceptível para além das páginas, em diferentes campos da arte que se conectam com as propriedades narrativas como é o caso do cinema. Logo, não é precipitado falar sobre distopia em Bacurau, uma vez que se trata de uma narrativa que agrega em sua construção signos da temática distópica, o que aproxima o cinema deste tropo literário. Um enlace que não é novo entre estas duas artes, que, mesmo autônomas, guardam entre si relações bastante íntimas. Desse modo, ao considerarmos a distopia como uma temática que surgiu na literatura, devemos também considerar sua propensão narrativa, que, como Gualda (2010, p. 204) argumenta, é um dos elos entre o cinema e a literatura, ao lado da impressão de realidade. Além disso, deve-se levar em consideração a própria associação do filme de Mendonça Filho e Dornelles ao chamado "cinema de gênero", como já citamos anteriormente, o que por si só lhe confere uma propriedade narrativa inextricável.

Desta maneira, atribuir as propriedades distópicas a Bacurau perpassa por uma conciliação entre as linguagens literária e cinematográfica, ambas pautadas na narração de uma sequência de eventos e na construção de um espaço-tempo 
característico. Este enlace entre as artes é possível a seu modo, considerando de que maneira ambas se apresentam, através da verbalidade e da iconicidade, respectivamente. Assim, através da representação das imagens distópicas que a literatura carrega consigo, é possível notar a transposição destas ideias para as telas, como são os casos de filmes famosos como Mad Max (1979) e Blade Runner (1982), além das adaptações de distopias literárias como Farenheit 451 (1962) e Nineteen EightyFour (1984).

Assim, levando sua narrativa de tons futurísticos e caóticos em consideração, atribuímos à Bacurau uma significação pautada na distopia e, mais especificamente, na distopia crítica, categoria que se tornou corrente a partir dos anos 1980 ao realizar uma intervenção na forma distópica característica e manifestar a imaginação utópica dentro das próprias distopias (MOYLAN, 2016, p. 151). Dito isto, passemos à análise.

\section{Réquiem para Matraga ou Bacurau enquanto distopia crítica}

A princípio, devemos levar em consideração alguns aspectos analíticos para que possamos julgar o filme como representante da distopia crítica. O primeiro deles, sem dúvida, é perceber que Bacurau não é um "lugar de matutos" como os seus adversários no filme os percebem, tampouco é uma comunidade que está subjugada ao poder opressivo que ronda a narrativa. Esta percepção inicial faz com que vejamos que não existe aqui uma distopia convencional, pois, mesmo que vivam numa condição isolada e oprimida, os moradores possuem tanto uma organização social bastante elaborada como um nível de especialização entre os personagens que faz com que as necessidades educacionais, médicas e sanitárias sejam atendidas suficientemente para que a sobrevivência seja efetiva.

Além disso, Bacurau oferece diversos tipos de ocupações e lazeres para os habitantes, aulas diárias para as crianças e adolescentes, trabalhos como os de feirante e comerciário, e até mesmo um trailer móvel que funciona como um bordel. Neste sentido, os habitantes procuram suprir as faltas existentes por meio da colaboração e respeito entre si, o que faz com que 
11 Intentional community, no original (tradução nossa)

$12[\ldots]$ a group of five or more adults and their children, if any, who come from more than one nuclear family and who have chosen to live together to enhance their shared values or for some other mutually agreed upon purpose (tradução nossa). todos consigam viver em relativa paz, mesmo com o descaso de autoridades.

Aqueles que estão à frente da comunidade são uma mulher médica e um professor negro, Domingas e Plínio, ambos com idade avançada e respeitados como detentores de saberes importantes, a saúde e a educação. Os dois são responsáveis por organizar as bases da cidade, que, mesmo sofrendo com a escassez de alimentos, e até mesmo de água, como é visto inicialmente no filme, não permitem que o local pereça. Além disso, ambos carregam consigo indicativos de gênero e de raça, respectivamente, o que nos faz retornar ao argumento de Cavalcanti (2011, p. 4) sobre a distopia crítica como uma narrativa que preconiza o discurso das minorias. Logo, ter estes dois representantes faz com que Bacurau seja uma resistência ao discurso hegemônico, irremediavelmente machista e racista.

Podemos pensar a distopia crítica de Bacurau também a partir da construção social da cidade como uma "comunidade intencional"11, o caso mais imediato de prática utópica colocada por Sargent. O autor as define como "um grupo de cinco ou mais adultos e seus filhos, se houver, que vêm de mais de uma família nuclear e que escolheram viver juntos para aprimorar seus valores compartilhados ou para algum outro propósito mutuamente acordado"12 (SARGENT, 1994, p. 15). No caso em questão, o propósito de Bacurau é sobreviver às adversidades impostas, de forma solidária e respeitosa, tal qual uma família, no sentido mais imediato da palavra.

Podemos confirmar esta afirmação já no enterro de dona Carmelita, outra personagem basilar para o entendimento do filme. Nestas cenas, é possível ver que todos se reúnem para lhe dar um último adeus e conseguimos perceber a força do luto que recobre estes sujeitos, os quais enxergavam nela uma figura essencial para o lugar, sobretudo na reação emocionada de Domingas, que demonstra a dor de alguém que perdera uma amiga de longa data. Por fim, o elo fica ainda mais evidente com o discurso de Plínio, filho da falecida, que ao citar a mãe, demonstra como ela fora importante para formar a comunidade, além de atentar para os problemas da região:

Eu queria aproveitar a participação de Domingas, que 'tá' visivelmente emocionada, 'né'? ‘Pra' falar um pouco de minha 
mãe, Carmelita! Carmelita teve filho, teve neto, neta, bisneto, afilhado, teve muito amigo. $\mathrm{Na}$ família tem de pedreiro a cientista, tem professor, tem médico, tem arquiteto, michê e puta, mas ladrão ela não gerou nenhum. Tem gente em São Paulo, Europa, Estados Unidos, tem gente na Bahia, Minas Gerais... E muita gente não pode vir aqui hoje prestar homenagem a ela por causa do problema da nossa região, mas eles mandaram muita ajuda, muita ajuda 'pra' Bacurau, e isso é prova de que Carmelita e Bacurau 'tão' em todos eles" (BACURAU, 2019).

Assim, pode-se perceber o poder de Carmelita, a qual foi formadora de muitas pessoas, que, mesmo tendo deixando Bacurau para trás eventualmente, sempre tiveram o senso de compartilhar o ideal solidário. Podemos depreender também que sempre existiu uma comunhão de ideias e valores na comunidade, isto porque os problemas tais quais nos sãos apresentados parecem existir há muito tempo ali, bem como a resistência da população a eles. Também é interessante ver como o personagem relata as posições dos parentes de Carmelita, não diminuindo nenhuma das profissões que cada um decidiu tomar, mas sim atribuindo-lhes respeito, ou seja, tratando a todos como iguais.

Na primeira parte do filme, acompanhamos o dia a dia da comunidade e sua organização. Além disso, conhecemos figuras importantes do lugar como Teresa, os já citados Plínio e Domingas, o verdureiro Damiano e Acácio, conhecido como Pacote, ex-membro do bando de Lunga, uma espécie de cangaceiro foragido, que também tem papel importante no correr da narrativa. Lunga e suas ações rebeldes contra os poderosos aos poucos se tornam um símbolo da resistência em Bacurau, os quais compreendem que seus atos violentos são em prol dos interesses de todos que estão ali e por isso onde quer que estivesse tinha o mesmo respaldo de um morador. Podemos confirmar essa afirmação quando, nos momentos iniciais, vemos Teresa e um outro personagem, Erivaldo, comentarem que não iriam entregá-lo/la.

TERESA - 'Tão' procurando Lunga.

ERIVALDO - E a recompensa que 'tão' pagando pela cabeça dela é boa.

TERESA - Não conte comigo 'pra' entregar Lunga. ERIVALDO - Nem comigo" (BACURAU, 2019). 
Percebemos como o conceito de Sargent é observável nesse caso, em que mesmo se tratando de um criminoso aos olhos da lei, ainda assim essa pessoa era alguém importante para o seu lugar. Mesmo que saibamos ao final do filme que o sentimento de gratidão ao personagem não se dá apenas pela proteção que proporciona ao povoado, uma vez que as autoridades haviam lhes virado as costas, era muito mais crível aliar-se a alguém que já havia feito parte da comunidade e que confrontava aqueles que detinham o poder em busca de melhorias do que qualquer outro que não fazia o mínimo esperado.

Outro caso que comprova os valores compartilhados dos habitantes é quando todos eles se escondem do prefeito, o corrupto Tony Jr. Personagem-símbolo do coronelismo no interior, o político adentra a cidade em época de eleição com uma chamativa carreata que conta com caminhões que levam donativos e livros, além de um terceiro veículo que toca a música de sua campanha eleitoral. Sua intenção é passar a imagem de que é um bom governante que ajuda o lugar que administra, o que não passa de uma mentira, dada a reação dos personagens. Avisados pela travesti Darlene, que tem um bar a alguns quilômetros da entrada de Bacurau, os habitantes "somem", adentrando suas casas e retirando todos os seus utensílios das ruas, deixando o lugar com um aspecto de cidade fantasma.

Um aspecto que chama atenção é a comunicação coordenada dos moradores, pois no exato momento em que Darlene envia uma mensagem de voz pelo seu celular, ela logo é escutada por todos levando à ação de se esconder. Aqui, o estereótipo do "matuto" que as pessoas do interior possuem também é quebrado, não apenas pelo uso compartilhado e efetivo da tecnologia, mas também pelo rápido poder de organização social, visto que muitas pessoas destas regiões costumam ser tidas como ignorantes, deixando-se levar pelas palavras dos políticos. Em contrapartida, o que ocorre em Bacurau é um domínio do discurso, que "manifesta-se pelo uso social e antissocial da linguagem" (MOYLAN, 2016, p. 81), ou seja, a população sabe tanto quando deve ficar em silêncio (ao se esconder de Tony Jr.), como também sabe o momento de se impor para reivindicar seus direitos (quando se exaltam contra a canalhice do político). 
Nossas considerações entram em consonância com Araújo, que percebe Bacurau como uma "utopia imersa na pobreza", uma cidade sem preconceitos, onde "os personagens são homens, mulheres, brancos, homossexuais, heterossexuais, transgêneros e vivem perfeitamente ali. $O$ filme nos leva à hipótese de uma sociedade sem preconceitos muito antigos" (ARAÚJO apud CASTANHO, 2020, s/p). É importante ver como a cooperação e o respeito mútuo de todos se entrelaça independentemente de condição física, ocupação ou orientação sexual. Até mesmo Lunga, o grande herói (ou anti-herói) da narrativa, é alguém que mina as relações habituais de gênero ao ser referido ora no masculino, ora no feminino, conferindo-lhe uma androginia característica, e quebrando o mito do "cabra macho" sertanejo, que, envolvido por sua masculinidade, salvaria a todos. Também é importante observar que o ataque que vem de fora é de ordem hegemônica e que se dedica a dizimar aquela diversidade de sujeitos e desapropriar o seu discurso (BACCOLINI; MOYLAN, 2003), reconfirmando mais uma vez o caráter distópico.

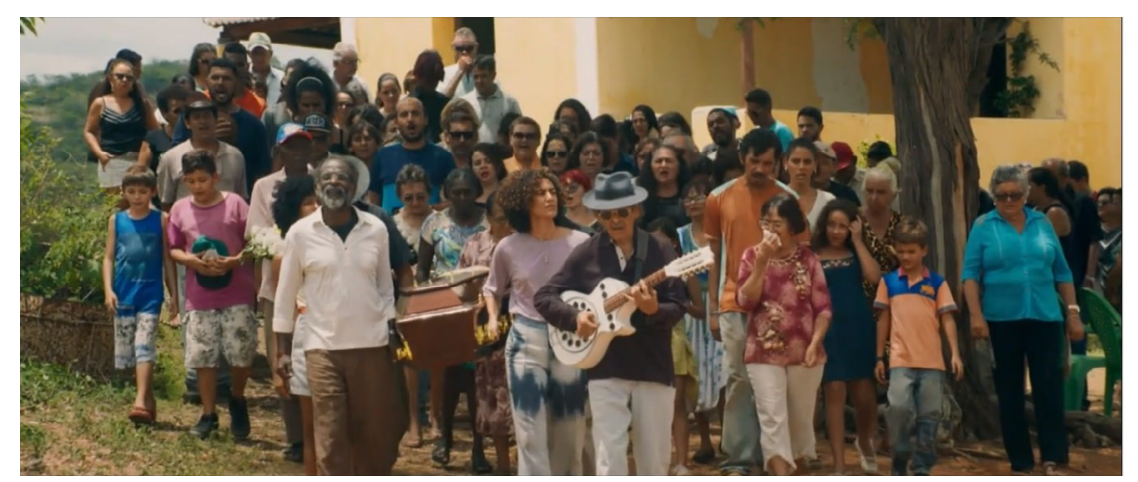

Figura 1 - A diversificada população de Bacurau durante o cortejo de dona Carmelita.

Fonte: Bacurau. Direção de Kléber Mendonça Filho e Juliano Dornelles. São Paulo: Vitrine Filmes, 2019.

Estes fatores organizacionais da comunidade Bacurau dialogam diretamente com as considerações de Baccollini, a qual afirma que a distopia crítica mantém um núcleo utópico ao criar um espaço de contestação e oposição "para aqueles grupos (mulheres e outros grupos 'excêntricos' cuja posição de sujeito não é contemplada pelo discurso hegemônico) para os quais a subjetividade ainda tem de ser alcançada" 
(BACCOLLINI, 2000, p. 18). Assim, o filme parte de uma lógica pessimista quando, logo nas cenas iniciais, surge um acidente envolvendo um caminhão funerário e uma motocicleta, o que espalha caixões pela estrada, e a visão de uma barragem onde a água é retida por pessoas desconhecidas e protegida por guardas que não deixam ninguém se aproximar. No entanto, esse crescente pessimismo é amainado quando vemos as relações interpessoais das pessoas do vilarejo, respeitosas e autossuficientes, independentemente das condições em que se encontram.

Nisto, as subjetividades destes indivíduos, que, mesmo vivendo em situação de opressão e revelia, aflora de uma maneira que conseguimos nos relacionar com seus problemas. Assim, sua ânsia por resistir fica evidente, quando o caráter antiutópico inicial é transposto para uma posição utópica que rejeita um possível estado de sujeição característico nas distopias genéricas. Então, mesmo que o espaço se construa em torno de uma situação de antiutopia, a comunidade demonstra um potencial avesso.

Esta ânsia por resistir se relaciona com as proposições de Moylan, o qual admite uma agenda mais decisiva nas distopias críticas, ao argumentar que elas são textos que, além de darem voz e espaço a sujeitos negligenciados socialmente, também:

[...] seguem a explorar meios de mudar o atual sistema, de modo que tais grupos marginalizados cultural e economicamente não apenas sobrevivam, mas também tentem se movimentar parar criar uma realidade social que seja moldada por um impulso em direção à autodeterminação humana e à saúde ecológica em lugar de uma realidade social constringida pela lógica restrita e destrutiva" (MOYLAN, 2016, p. 143).

Ou seja, elas assumiriam uma postura militante em face à realidade totalizadora em que foram escritas, apontando para a sua aguçada leitura política que reforça o caráter cronotópico que possuem. Bacurau não corre para longe desta interpretação, pois é, sem dúvidas, um filme político, como já foi pontuado, com um teor de diálogo com as problemáticas que sondam o Brasil, como a falha antinomia histórica entre Sul e Norte do país, algo que fica evidente na fala dos forasteiros sulistas que alegam que não são iguais às pessoas de Bacurau por serem 
de uma "região diferente e mais rica do país", e, por isso, mais parecidos com os estrangeiros que aparecem no filme.

Dessa maneira, podemos fazer uma associação das relações interpessoais em Bacurau não apenas com os ataques às minorias sociais, mas também com a desigualdade social no Brasil, já que estamos falando de um espaço culturalmente diversificado e que sofre constantes de um grupo de valores supremacistas. Aqui concluímos que o filme, ao desvelar a história desta comunidade que vive à sombra de uma autoridade hegemônica, assume um papel dessacralizante, $\mathrm{o}$ qual não está apenas atrelado à narrativa, mas à própria escolha dos diretores em conseguir um povoado isolado no interior do Rio Grande do Norte e colocar os próprios habitantes como parte do elenco ao lado dos demais atores, o que lhe confere um tom verossimilhante que dialoga com o espaço que representa ficcionalmente.

Voltando ao plano narratológico, acompanhamos o filme entrar em seu ponto conflitante desde que a mesma ordem hegemônica começa a agir quando percebe a contrariedade que está se formando entre as pessoas do povoado. Uma série de eventos começa a traçar o caminho para o extermínio de Bacurau, pois é evidente que um sinal de oposição como aquele deve ser visto como ameaça e precisa desaparecer antes que seja tarde demais. Eis que surge um grupo de estrangeiros que, a serviço de "gente importante", acumula pontos ao assassinar pessoas e dizimá-las em sua trajetória. Comandados pelo excêntrico Michael, um alemão radicado nos Estados Unidos, o grupo começa aos poucos a se infiltrar na vida de Bacurau, fazendo com que o lugar desapareça.

Aqui o caráter distópico volta à tona com toda força, enquanto as forças de dominação tentam se apoderar daquela utopia projetada. Inicialmente, o processo se dá de maneira sorrateira e por meio de atos que, por um momento, passam despercebidos, como é o caso do apagamento do povoado dos mapas por satélite, assim como a vistoria do local por meio de um drone que só é percebido por uma pessoa. A próxima fase do projeto acontece com o assassinato de uma família que vivia numa fazenda e o bloqueio do sinal de telefone da área, feito através de dois forasteiros, um homem e uma mulher do sudeste do Brasil, que surgem no lugar sob o pretexto de estarem fazendo trilha pela região. Abaixo, transcrevemos os 
diálogos de uma reunião do grupo, em que todos os detalhes de seu plano de destruição são revelados:

MICHAEL - Jake e Terry concluíram com sucesso a primeira missão ontem à noite na "hacienda" Taraiu.

FORASTEIRO - Tarairú.

MICHAEL - Tanto faz.

TERRY - Foi difícil, mas nós conseguimos.

JAKE - Foi intenso. Estou pronto para ir para casa. Missão cumprida. Foi louco.

MICHAEL - Estamos em contagem regressiva agora... Como está a situação do bloqueador de sinal?

KATE - Está bloqueado. O sinal foi derrubado. Eles estão literalmente fora do mapa.

FORASTEIRO - As pessoas em Bacurau estavam reclamando do sinal. E o lugar não está mais no mapa. Portanto... funciona. MICHAEL - Cortamos a eletricidade amanhã?

KATE - Eles vão acionar o gerador, mas até lá teremos pânico. MICHAEL - E o caminhão?

WILLY - Está pronto. Os prestadores de serviço locais não decepcionaram.

MICHAEL - Ótimo... E a estrada?

FORASTEIRA - A estrada foi bloqueada. Ninguém passa de Serra Verde por causa das pessoas que estamos pagando para isso. E também não vai ter feira nos próximos dias. Vai ser tranquilo.

JAKE - E nada de polícia, certo?

FORASTEIRO - Não tem polícia aqui. (BACURAU, 2019).

As falas, juntamente à atuação precisa dos atores, deixam transparecer o tom de desdém que tanto os estrangeiros quanto os dois brasileiros sulistas têm por aquela população, que os tomam como um simples serviço a ser feito, mesmo se tratando de uma chacina. Em um dos personagens, Josh, o tom é ainda mais incisivo e perverso, pois ele questiona o porquê de todos aqueles preparativos, que julga desnecessários, quando as coisas poderiam ser feitas mais rapidamente:

JOSH - Com licença. Acho incrível que o sinal esteja bloqueado por satélites alinhados a laser, que o prestador vai cumprir o serviço com o caminhão, mas nós temos armas. 
Nós temos munição, certo? Então, o que estamos esperando? Que porra estamos fazendo nessa reunião de merda numa fazenda longe de tudo tirando palitinhos para ver quem sai de fininho para acabar com o caipira "Pablo"? Que tal pularmos para a parte em que carregamos as armas e vamos para a cidadezinha fazer um estrago! Eu estou aqui pelo número de mortos. Vamos nessa, caralho! Vamos!

Nestas cenas em particular, quando conhecemos os algozes de Bacurau, percebemos o caráter daqueles que detém o poder hegemônico, pois, se de um lado Bacurau é uma terra essencialmente miscigenada e pobre, os americanos são brancos e detentores de um arsenal tecnológico, e, consequentemente, financeiro, bastante elevado. Observamos também o forte teor de xenofobia presente nestes sujeitos, não apenas contra as pessoas de Bacurau, mas até contra os próprios aliados brasileiros. Quando os sulistas expressam sua opinião, afirmando-se superiores e mais parecidos com os estrangeiros, o grupo zomba deles, ao alegarem que isso é uma mentira e que eles compõem uma estranha miscigenação, que os deixa longe de serem parecidos com pessoas brancas:

WILLY - Como podem ser como a gente? Somos brancos. Vocês não são brancos. Eles são brancos?

TERRY - Eu não sei, eles... Bom, sabe de uma coisa... Eles meio que parecem brancos, mas não são. Os lábios e nariz dela entregam, 'tá' vendo? Eles estão mais para mexicanos brancos. JAKE - Você poderia ser italiano. E ela poderia ser polonesa. JULIA - Eu acho que ele é um latino bonitão (BACURAU, 2019).

Logo, adota-se um tom supremacista vindo destes indivíduos, que desconsideram qualquer outro que não seja pertencente a seu próprio grupo como aliados. No caso dos sulistas, eles são apenas mais um mal necessário para alcançar o objetivo final: o fim de Bacurau. Por isso, mesmo que consigam deixar a cidade sem comunicação móvel, os dois forasteiros sulistas acabam sendo mortos pelos estrangeiros como retaliação por terem se envolvido com o assassinato de dois moradores durante a visita a Bacurau.

O plano parece bem-sucedido, no entanto, o grupo de extermínio não contava com a união "daquelas pessoas 
matutas" em torno do seu ideal de sobrevivência. O assassinato dos dois moradores é um ponto decisivo na narrativa, pois, ao perceber que aquilo era apenas o início de um problema maior, Acácio vai até o esconderijo de Lunga e mostra os cadáveres mortos pelos sulistas, informando-o de toda a estranha situação que está acontecendo em Bacurau. Também Damiano, que vira o drone sobrevoando as redondezas, avisa sobre a aparição, apenas reforçando a necessidade de se proteger.

Aqui adentra outro elemento essencial para compreender a distopia crítica no filme, a memória, que, quando é reapropriada por meio da linguagem, possui um papel empoderador para os personagens oposicionistas. De acordo com Moylan, lembrar é importante para a resistência existir nas distopias, na medida "em que a re-visão textual recupera memórias do passado oposicionista (com suas histórias de resistência e mudança) e recruta essas memórias prospectivas no trabalho de articulação dos próximos passos políticos" (MOYLAN, 2016, p. 144). Para Baccolini (1996, p. 345), a memória age como um nó utópico, que está atrelado a uma era de ouro dos protagonistas, o que reitera a possibilidade de oposição, já que fornece um sentido à vida desses sujeitos ao trazer de volta informações que estimulam seu potencial de crítica.

De acordo com Figueiredo (2015, p. 84), a memória na distopia faz parte de um "saber não oficial" relacionado com o discurso vigente, gerando embate. A autora também afirma que o ato de recordar "é sinônimo de ter esperança e de perceber que o regime estabelecido não é eterno, uma vez que houve algo antes da sua existência" (FIGUEIREDO, 2015, p. 85). Assim, lembrar é antes de tudo uma forma de resistência, é a possibilidade de transformar a opressão e a morte trazida pelos estrangeiros em um momento de paz, que, de alguma forma, assegura a continuidade de Bacurau no mapa, numa transformação da utopia enquanto imaginação para utopia enquanto consciência (BACCOLINI, 2000, p. 30).

Por isso, quando as pessoas começam a morrer, o chamado à ação retorna para a figura de Lunga, e, mesmo que seja "alguém que vale mais pelo mal do que pelo bem que pode fazer" (BACURAU, 2019), como comenta Damiano, acaba se tornando a única opção de defesa naquele momento extremo. $\mathrm{O} / \mathrm{a}$ fora-da-lei carrega consigo um signo de violência, que, se no início parece gratuita, "toma um rumo diferente 
ao retratar o passado e presente. A rebelião e a inquietude de agir em prol do funcionamento daquela sociedade, que parece funcionar longe dos desmandos de um governo estúpido" (MACHADO, 2019, s/p). O/a personagem é o chamado a um passado de persistência pela vida e não é sem motivos que ele/ela é o único/a que pode conter a perigosa situação que se delineia, tornando-se, assim, garantia de um futuro por meio de uma volta ao passado.

A memória começa a tomar forma de imediato no reencontro, pois, quando Acácio explica a situação e pede ajuda para Lunga, a primeira pergunta que faz para o ex-parceiro é: “Tu vai voltar a ser Pacote?" (BACURAU, 2019), como que para lembrar de sua identidade pregressa e acender uma lembrança do tempo em que atuavam juntos. Enquanto a resposta fica suspensa pela voz do personagem, a cena seguinte torna-se uma confirmação quando ele volta a Bacurau e vê os habitantes assistirem a um malfadado vídeo que compila imagens de câmeras de segurança que capturaram os dez melhores assassinatos do "Rei do Teco Pacote". Surgindo por trás dele, Lunga se mostra pronto/a para organizar um plano de ação contra o ataque dos americanos, que estava para acontecer no dia seguinte.

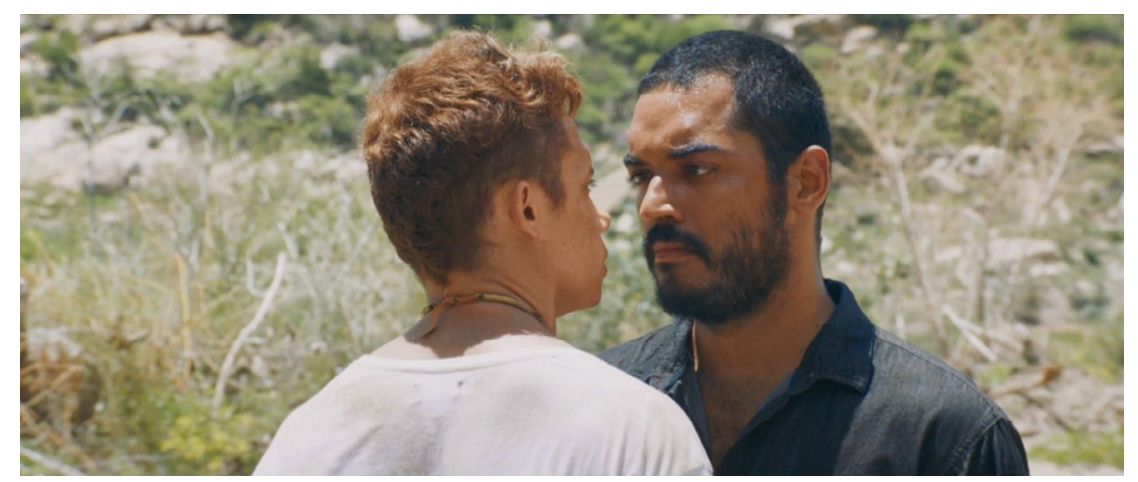

Figura 2 - Acácio pede ajuda a Lunga

Fonte: Bacurau. Direção de Kléber Mendonça Filho e Juliano Dornelles. São Paulo: Vitrine Filmes, 2019.

Com a volta de Lunga, percebemos como os moradores de Bacurau estão envolvidos com o passado e, ao final do filme, esse fator torna-se crucial para a salvação do lugar das mãos dos estrangeiros. Um dos aspectos mais relevantes dessa retomada de narrativa é o pequeno museu da cidade, que, em seu papel de abrigar a história, traz mais uma vez 
à tona o elo eutópico que existe na narrativa. Sendo um item que passa despercebido em várias cenas ao longo do filme, pouco parece que o pequeno lugar terá importância tão crucial para o andamento da história. Durante a visita dos forasteiros sulistas que estão ajudando os americanos, notamos que eles são incitados a "visitarem o museu" pelos habitantes e, mesmo que o convite pareça sugerir apenas um simples chamado para conhecer uma das poucas atrações que a cidade tem a oferecer a seus visitantes, se notarmos suas propriedades, "é como se ele fosse a carteira de identidade daquele povo, um espaço legítimo e autorizado para Bacurau falar de si para o resto do mundo" (KUNZLER, 2019, s/p), guardando sinais de como aquele espaço ainda sobrevive.

Quando, na cena do ataque à cidade, um dos americanos, Terry, entra no interior do museu, deparamo-nos com várias lembranças relacionadas à resistência. Sabemos a partir de então da ligação íntima da cidade com o cangaço através de fotos, recortes de jornais e diversos utensílios que relacionam o lugarejo com o movimento de banditismo. O mais importante, no entanto, está ao fundo do museu em uma parede cheia de antigas armas de fogo, que, no momento em questão, não estão à mostra, mas sim nas mãos dos moradores que se escondem de seus algozes e esperam o momento certo para revidar. Além disso, a presença de duas passagens subterrâneas, uma no museu e outra no marco zero da cidade, completa a importância da lembrança de que os antepassados têm para a cidade ao retaliarem seus inimigos, o que respalda na própria criação de sua identidade.

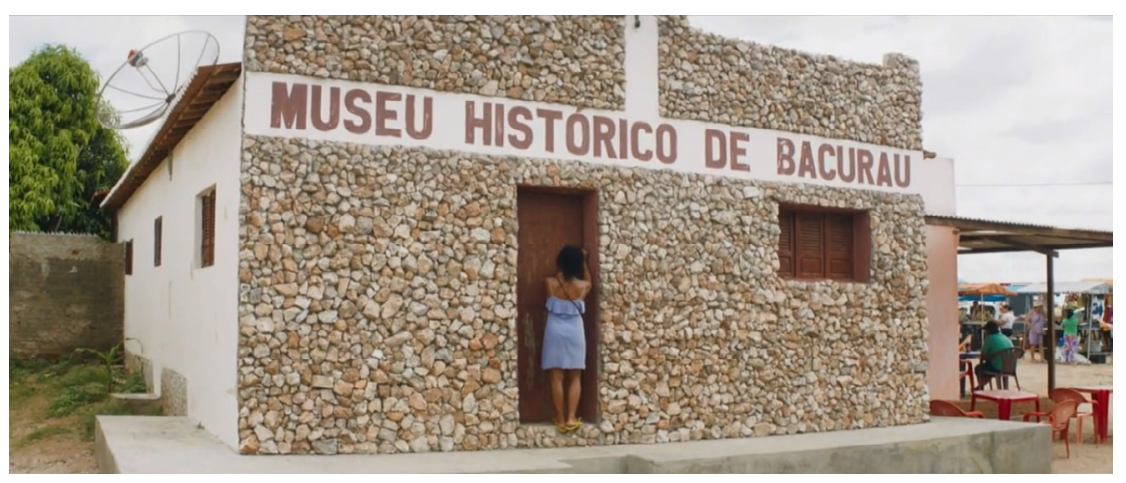

Figura 3 - O Museu Histórico de Bacurau, em uma das cenas iniciais do filme.

Fonte: Bacurau. Direção de Kléber Mendonça Filho e Juliano Dornelles. São Paulo: Vitrine Filmes, 2019. 
Podemos perceber que a passagem dos sulistas poderia ter sido menos problemática e/ou suspeita se eles ao menos tivessem visitado o museu no início do filme, o que configurouse como um erro fatal para os planos finais do grupo, já que eles poderiam ter sabido sobre o pesado armamento que a cidade possuía para se defender. Com isso, a singela casa que fica no meio da cidade não carrega apenas o passado de Bacurau, "como também a essência de um povo, o que poderia fazer com que eles evitassem muita coisa, diga-se de passagem" (MACHADO, 2019, s/p). E é exatamente o que ocorre quando os invasores são emboscados pela população e assassinados, exceto por seu líder, Michael, que numa das cenas mais significativas do filme, vê surgir o espírito de Carmelita diante de si como uma força que protege aquelas pessoas.

Esta aparição conversa diretamente com os dois aspectos que abordamos ao longo desta análise: o discurso do oprimido e a memória empoderadora. Carmelita, interpretada pela figura quase onírica de Lia de Itamaracá, recupera o passado do lugar e suas nuances de resistência, impressas no rosto daquela senhora negra, que fala por todos aqueles indivíduos pobres, de diferentes etnias e orientações e que apenas querem ter seu espaço no mundo sem complicações. Podemos assumir que Carmelita é Bacurau, como Plínio indiretamente afirma em seu discurso durante o velório, um "bicho brabo" que mesmo à revelia, detém o poder de modificar sua realidade.

O final é favorável àqueles que desafiam o sistema, contudo, isso não é suficiente para que a hegemonia seja derrubada de vez. Como sabemos, Tony Jr. estava associado aos estrangeiros no plano para a destruição da cidade, mas, assim como os sulistas, ele é apenas uma peça intermediária para um problema maior, e que logo todo aquele levante não teria significado nada. Aqui, o tom distópico volta a pairar, mostrando que os momentos de calmaria após aquilo serão momentâneos. Bacurau continua situada em um mundo contrário a seu sistema de vida e irremediavelmente sofrerá novas retaliações.

TONY JR. - Que foi que houve aqui gente? Cadê os 'gringo'? Os 'turista'?

LUNGA - Eles morreram. 
TONY JR. - Lunga, isso aqui é um rabo de foguete grande que vocês 'tão' se metendo. Esse povo é gente importante. O problema da água a gente resolve? Resolve. Agora, isso aqui não vai ficar barato não, Lunga. Eu mesmo vou morrer por causa disso. Isso aqui em menos de vinte e quatro horas vai virar cinza (BACURAU, 2019).

Outro fator que corrobora esta afirmação é quando somos mostrados a Michael falando para Teresa que seu grupo matou mais pessoas do que eles poderiam imaginar e, por fim, gritando de forma ameaçadora da masmorra onde é preso: "Isso é apenas o começo" (BACURAU, 2019). Por isso, quando, em uma cena anterior, o personagem tenta se suicidar, absorvemos que ele está ciente de que não importa se for ele a dar cabo do lugarejo, alguém mais forte viria e terminaria o serviço.

Assim, o filme termina com a esperança no ar depois da vitória dos protagonistas, mas ao mesmo tempo deixa uma pergunta no ar: estariam essas pessoas realmente a salvo? Esta é uma pergunta que o final aberto deixa que o espectador imagine enquanto a voz de Geraldo Vandré roga seu melancólico réquiem, o qual comunica que ninguém há de calar os pássaros bravos enquanto houver vida para viver e muito a se fazer e salvar.

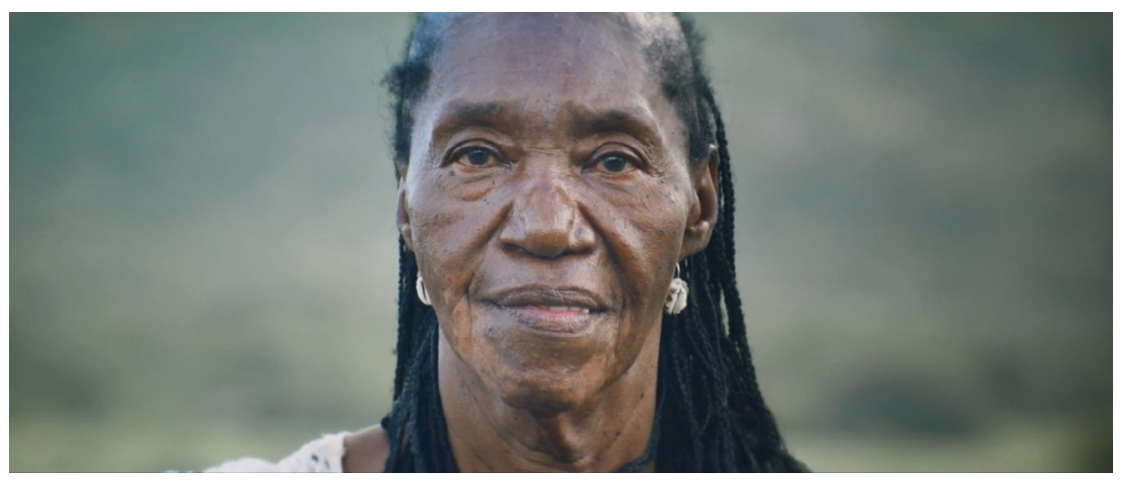

Figura 4 - O espírito de dona Carmelita surge diante de Michael.

Fonte: Bacurau. Direção de Kléber Mendonça Filho e Juliano Dornelles. São Paulo: Vitrine Filmes, 2019. 


\section{Considerações finais}

Bacurau é um filme propício para pensar sobre as problemáticas que envolvem o Brasil. Por meio de sua variada transição de gêneros, o filme consegue alegorizar um "país que não consegue se olhar no espelho" (CASTANHO, 2020, $\mathrm{s} / \mathrm{p})$ e que, rumando a um futuro desconhecido, não resolve problemas que se estendem por toda a sua história. No entanto, o filme não fala de problemas que estão relacionados apenas ao Brasil, ou o mesmo não teria sido tão comentado como foi em outros países. Bacurau fala dos pobres, das classes menos privilegiadas, das sexualidades que fogem ao padrão normativo e como elas lutam para coexistir num espaço de luta pela sua narrativa. Desta forma, eles vivem em uma distopia constante, em que são oposição à uma hegemonia que não mede esforços para apagar sua existência.

Portanto, fica claro porque a população de Bacurau tenta reverter esse quadro ao criar um sistema ideal de vida, que consiste na colaboração de todos os indivíduos para superar qualquer revelia externa. Compreendendo pessoas de diversos nichos sociais, a pequena cidade consegue sobreviver criando uma comunidade intencional, que, mesmo em meio a pobreza e o isolamento espacial, constrói um elo utópico que se difere da realidade hegemônica e alheia em que vivem. Então, ao carregar em sua narrativa signos que ao mesmo tempo se aproximam do pessimismo de uma não utopia, mas também da esperança característica da utopia, Bacurau assume a forma de uma distopia crítica, forma narrativa paradoxal que surgiu nos parâmetros da ficção científica durante os anos 1980 e 1990, e reavivou a utopia literária, ao imaginar uma sociedade que é "pior do que a sociedade contemporânea, mas que geralmente inclui, pelo menos um enclave eutópico ou apresenta a esperança de que a distopia possa ser superada e substituída

$13[\ldots]$ worse than contemporary society but that normally includes at least one eutopian enclave or holds out hope that the dystopia can be overcome and replaced with a eutopia (tradução nossa). por uma eutopia ${ }^{13 \prime \prime}$ (SARGENT, 2001, p. 148).

Como pudemos acompanhar em nossa análise, a narrativa transita entre as antinomias históricas, e, enquanto em um momento se alinha às proposições distópicas, no outro acaba se juntando à utopia através do discurso do oprimido e da memória empoderadora destes sujeitos. Assim, o filme mostra personagens em situação desfavorável, mas que nem por isso se tornam sujeitos subjugados a seus algozes que lhes 
roubam recursos e até mesmo tentam acabar com suas vidas, chegando até mesmo a recorrer à violência para conseguirem manter seu discurso vivo. A figura do museu e a lembrança do cangaço ocorrem aos personagens como meio de resistir, contrapondo o antigo caráter negativo que o movimento possui e se tornando símbolo de um passado que luta para não desaparecer e por isso lembrar-se é crucial.

Aqui nos recordamos das palavras de Hutcheon, que, ao observar a escrita pós-moderna e seu caráter paradoxal, percebe como é dada uma vazão para a exploração de discursos que comumente não aparecem na história oficial, pois, se tanto o literário como o histórico são apenas discursos, não é possível tratá-los por meio de uma lógica de verdadeiro ou falso e o que existe agora são apenas "verdades". Assim, essas ficções sugerem uma reescritura ou reapresentação do passado como maneira de apresentá-lo ao presente sem atribuir conclusões ou teleologias (HUTCHEON, 1991, p. 147). O mesmo ocorre na distopia crítica, que pode ser observada como pós-moderna em razão de sua inadequação ao fechamento narrativo e ao discurso dominante, e também em Bacurau, que, ao alçar sua narrativa contra um ambiente hegemônico, torna-se um grande representante destas considerações.

\section{REFERÊNCIAS}

BACCOLINI, Raffaella; MOYLAN, Tom (orgs.). Dark horizons: science fiction and the dystopian imagination. New York, London: Routledge, 2003.

BACCOLINI, Raffaella. Gender and genre in the feminist critical dystopias of Katharine Burdekin, Margaret Atwood, and Octavia Butler. In: BARR, Marleen. (org.). Futures females, the next generation: new voices and velocities in feminist science fiction criticism. Lanham: Rowman \& Littlefield, 2000. p. 13-34.

Journeying through the dystopian genre: memory and imagination in Burdekin, Orwell, Atwood, and Piercy. In: BACCOLINI, Raffaella; FORTUNATTI, Vita; MINERVA, Nadia. (orgs.). Viaggi in utopia. Ravenna: Longo, 1996. p. 343-357.

BACURAU. Direção de Kléber Mendonça Filho e Juliano Dornelles. São Paulo: Vitrine Filmes, 2019. 1 DVD. 
BAKHTIN, Mikhail. Questões de literatura e de estética: a teoria do romance. 2. ed. São Paulo: Hucitec, 1990.

BLOCH, Ernst. O princípio esperança. v. 1. Rio de Janeiro: Contraponto, 2005.

CASTANHO, Laura. Para debatedores, 'Bacurau' é alegoria de um país que não consegue se encarar no espelho. Disponível em: https:// www1.folha.uol.com.br/ilustrada/2020/02/para-debatedoresbacurau-e-alegoria-de-um-pais-que-nao-consegue-se-encararno-espelho.shtml. Acesso em: 15 mar. 2020.

CAVALCANTI, Ildney. Às margens das margens, o futuro do futuro: o espaço-tempo utópico em Body of Glass, de Marge Piercy. IN: SEMINÁRIO MULHER E LITERATURA - GÊNERO, IDENTIDADE E HIBRIDISMO CULTURAL. 3., 2007, Ilhéus. Anais eletrônicos do..., UESC, 2007. Disponível em: http://www.uesc.br/seminariomulher/anais/PDF/Mesas/ ILDNEY\%20CAVALCANTI.pdf. Acesso em: 29 jul. 2020.

FITTING, Peter. A short story of Utopian Studies. Science fiction studies, Greencastle, v. 36, n. 1, p. 121-131, mar., 2009.

FIGUEIREDO, Carolina Dantas de. Memória e poder nos regimes distópicos. Papéis - Revista do Programa de PósGraduação em Estudos de Linguagem da UFMS, Campo Grande, v. 19, n. 38, p. 83-98, 2015.

GUALDA, Linda Catarina. Literatura e cinema: elo e confronto. MATRIZES, São Paulo, v. 3, n. 2, p. 201-220, 2010.

HUTCHEON, Linda. Poética do pós-modernismo: história, teoria, ficção. Rio de Janeiro: Imago, 1991.

KUNZLER, Josiane. Por que Bacurau tem um museu?. Disponível em: https://projetocolabora.com.br/ods4/por-que-bacurautem-um-museu/. Acesso em 30 jul. 2020.

MACHADO, Vinícius. O museu de Bacurau e a resistência pela existência. Disponível em: https://medium.com/neworder/ o-museu-de-bacurau-e-a-resistência-pela-existência88c07bfb3325. Acesso em: 30 jul. 2020. 
MENDONÇA FILHO, Kléber. Kleber Mendonça Filho: “Não fiz um panfleto". Entrevista concedida a Fernando Molica e Bruna Motta. Revista Veja, São Paulo, n. 2654. Disponível em: https://veja.abril.com.br/entretenimento/kleber-mendoncafilho-bacurau/. Acesso em: 14 jul. 2020.

MORE, Thomas. Utopia. Belo Horizonte: Autêntica, 2016.

MOYLAN, Tom. Demand the impossible: science fiction and the utopian imagination. New York: Methuen, 1986.

MOYLAN, Tom. Distopia: fragmentos de um céu límpido. Maceió: Edufal, 2016.

PAVLOSKI, Evanir. 1984: a distopia do indivíduo sob controle. Ponta Grossa: Editora UEPG, 2014.

SARGENT, Lyman Tower. The three faces of utopianism revisited. Utopian studies, Missouri, v. 5, n. 1, p. 1-37, 1994.

SARGENT, Lyman Tower. US eutopias in the 1980s and 1990s: self-fashioning in a world of multiple identities. In: SPINOZZI, Paola (Org.). Utopism/Literary utopias and national cultural identities: a comparative perspective. Bologna: COTEPRA/ University of Bologna. 2001. p. 137-148.

SARGENT, Lyman Tower. Utopianism: a very short introduction. London: Oxford, 2010. 


\section{ABSTRACT \\ Chronicle of an Announced Resistance: the Traces of Critical Dystopia in Bacurau, by Kléber Mendonça Filho and Juliano Dornelles}

Dystopia is an unfolding of the literary utopia that gained strength especially in the early twentieth century, demonstrating a unique ability to discuss current socio-political issues through a "stained mirror of the future". The dystopian text has a predisposition for the narrative that brings it closer to different artistic and discursive genres when telling the experience of one or more people in the near future or not, in which the proposed social order is considered worse than what exists in the reality. From the 1980s, critics and theorists who study the theme signaled a "dystopian turn", in which narratives of this nature began to show glimpses of hope amid the characteristic chaos of the theme with the advent of the so-called critical dystopias. Taking the above considerations, the present work analyzes the recent feature film by Brazilian directors Kléber Mendonça Filho and Juliano Dornelles, Bacurau (2019) as a critical dystopia. The film, which places its narrative in the Pernambuco hinterlands "in a few years", presents the union of a community against the constant tension of external forces that worked for its destruction, leaving them with only the sense of resistance already rooted in its history. Thus, we seek to discuss this specific type of dystopia and how it is present within the narrative of the film, transforming it into a material of acute social and political criticism. The present research is bibliographic and has exploratory character, based theoretically on names as Sargent (1994), Baccolini (2003) and Moylan (2016).

Keywords: Critical dystopia. Utopianism. Bacurau. 
José Wanderson Lima Torres é Doutor em Estudos da Linguagem pela UFRN. Professor do Mestrado Acadêmico em Letras da UESPI, possui experiência na área de Letras, com ênfase em Literatura, atuando principalmente nas seguintes linhas: Teoria Literária e Literatura Comparada. É editor da revista eletrônica dEsEnrEdoS.

Wagner dos Santos Rocha é Licenciado em Letras/Português pela UESPI. Atualmente é mestrando pelo Programa de Pós-Graduação em Letras da mesma instituição. Possui experiência na área de Letras, com ênfase em Literatura. 